\title{
Morbidity and mortality of car occupants: comparative survey over 24 months
}

\author{
M S CHRISTIAN
}

\begin{abstract}
The severity of injuries sustained by 2577 car occupants in road traffic accidents in the catchment area of one district accident service during February 1982 to January 1984 inclusive was assessed using the injury severity score system.

In the first $\mathbf{1 2}$ months the mean injury severity score for front seat occupants injured in a road traffic accident was 4.94 and in the second 12 month period, after the implementation of the seat belt law, the mean injury severity score of all injured front seat occupants was $2 \cdot 80$. These figures indicated a reduction in injury severity of front seat occupants of $53.4 \%$ on the previous 12 month figures. The severity of injury sustained by unbelted front seat occupants and back seat passengers showed no significant change over the two years.

The number of front seat occupants killed or sustaining serious injuries (injury severity score greater than 12) showed a reduction of $54 \%$ in the 12 months beginning February 1983. Front seat occupants requiring admission for injuries sustained showed a decline of $42 \%$ in the 12 months after the introduction of the seat belt law, and deaths among front seat occupants fell by $27 \%$ compared with the previous 12 months. After the implementation of seat belt legislation those front seat occupants killed or sustaining serious injuries included a significantly higher proportion of victims who were not wearing their seat belts or showed positive evidence of alcohol intake at the time of the accident.
\end{abstract}

This series suggests that the incidence of serious injury or deaths among front seat occupants of cars has decreased substantially since the seat belt law became effective on 31 January 1983.

\section{Introduction}

Since 1969, when Queensland, Australia, became the first state to introduce legislation making compulsory the wearing of seat belts by front seat occupants of cars, many workers have noted how the wearing of seat belts has resulted in a substantial reduction in the morbidity and mortality ${ }^{1-3}$ of car occupants involved in road traffic accidents. Even before legislation became effective in the United Kingdom papers from Britain reported a decrease in severity of injury sustained by front seat occupants who were belted at the time of the accident. ${ }^{4} 6$

Various systems have been used to indicate severity of injury, including relating the length of stay in hospital to severity ${ }^{7}$ and classifying injuries into minor, serious, and fatal. The International Classification of Diseases and Injury ${ }^{8}$ has also been suggested as

Wexham Park Hospital, Slough SL2 4HL

M S CHRISTIAN, MB, FRCS, consultant in accident and emergency medicine relevant; it, however, indicates the anatomical site of injury but not its severity. In 1974 a system was introduced by Baker et al in the United States quantifying severity of injury (abbreviated injuries scale 76). ${ }^{9}$ In that system seven body regions are defined and injuries in each scored according to the code. These range from a score of 1 , for the most minor, to 6 , defined as injuries currently unsurvivable in the light of present knowledge. From that information is derived the injury severity score, which is the sum of the square of the highest totals obtained in three separate regions. The scoring system was amended in $1980^{10}$ and is a measure of the severity of injury, and not necessarily a prognostic index. Since 1966 the abbreviated injuries scale 76 and latterly the abbreviated injuries scale 80 have been widely used and internationally accepted as a means of assessing severity of injury and, although primarily designed for use in injuries sustained in road traffic accidents, have been used effectively in assessing severity of injury in various circumstances. 112 The use of injury severity scoring combined with clinical assessment probably provides the most accurate method at the moment of clarifying severity of injuries.

\section{Methods}

In the 24 months beginning February 1982 the notes of all patients brought to hospital after a road traffic accident were perused and information about the accident and details of injury sustained extracted and recorded. An injury severity score was assessed by one person only, and for those patients who were admitted follow up of the patient and the inpatient notes were used in order to amend the final score. This information was supplemented by questionnaires sent to patients when information from clinical notes or initial clinical examination was inadequate for accurately assessing the final severity of injuries.

For those patients who died as a result of injuries sustained in road traffic accidents a provisional injury severity score was allocated from an initial assessment in the accident department, the final score being obtained by studying postmortem findings. In both fatal and non-fatal cases when details of the accident were either not available or inadequate the police and ambulance service records were helpful in supplementing information. Occupants of heavy goods vehicles and public service vehicles were excluded from the survey.

\section{Results}

In the 12 months before the introduction of seat belt legislation 1103 front seat occupants sustained non-fatal injuries. Of these, exactly one third were wearing seat belts and the mean injury severity score was $4 \cdot 104$ (table I). In the first 12 months after seat belt legislation a total of 1042 front seat occupants sustained non-fatal injuries; $85.6 \%$ were wearing seat belts and the mean injury severity score was $2 \cdot 17$. In the first 12 month period up to the end of January 1983, 18 front seat occupants were killed; their mean age was 54.2 years and their mean injury severity score $51 \cdot 8$. In the next 12 months 13 front seat occupants were killed; their mean age was 27.9 years and their mean injury severity score $55 \cdot 5$.

TABLE I-Seat belt wearing rates and injury severity scores of front seat occupants sustaining non-fatal injuries during February 1982 to 7 anuary 1984

\begin{tabular}{|c|c|c|c|c|c|c|c|c|c|c|c|c|}
\hline & February & March & April & May & June & July & August & September & October & November & December & January \\
\hline \multicolumn{13}{|c|}{$1982-3$} \\
\hline $\begin{array}{l}\text { \% Seat belt wearers } \\
\text { Mean injury severity score }\end{array}$ & $\begin{array}{l}25 \\
3 \cdot 75\end{array}$ & $\begin{array}{c}27 \\
3 \cdot 50\end{array}$ & $\begin{array}{c}25 \\
4 \cdot 50\end{array}$ & $\begin{array}{c}48 \\
2 \cdot 80\end{array}$ & $\begin{array}{l}22 \\
3 \cdot 75\end{array}$ & $\begin{array}{c}26 \\
4 \cdot 50\end{array}$ & $\begin{array}{c}33 \\
4 \cdot 00\end{array}$ & $\begin{array}{c}36 \\
6 \cdot 50\end{array}$ & $\begin{array}{c}30 \\
4 \cdot 80\end{array}$ & $\begin{array}{c}32 \\
3 \cdot 75\end{array}$ & $\begin{array}{c}43 \\
3 \cdot 60\end{array}$ & $\begin{array}{c}52 \\
3 \cdot 80\end{array}$ \\
\hline \multicolumn{13}{|c|}{$1983-4$} \\
\hline$\%$ Seat belt wearers & 92 & 94 & 84 & 89 & 80 & 84 & 84 & 84 & 91 & 88 & 89 & 81 \\
\hline Mean injury severity score & $1 \cdot 75$ & $2 \cdot 70$ & $2 \cdot 75$ & $1 \cdot 50$ & $1 \cdot 50$ & 1.75 & $2 \cdot 75$ & $2 \cdot 70$ & $1 \cdot 50$ & $3 \cdot 25$ & $2 \cdot 10$ & $2 \cdot 00$ \\
\hline
\end{tabular}


Injuries sustained by front seat occupants who were killed in the period February 1983 to January 1984 were studied in depth. Of the 13 who died, eight were not wearing a seat belt, and in none of these cases was there any appreciable intrusion of the front compartment of the vehicle. Six of these eight front seat occupants were unbelted drivers' whose mean blood alcohol concentration was $147.5 \mathrm{mg} / \mathrm{dl}(32.0 \mathrm{mmol} / \mathrm{l}) .^{13}$ Four of the front seat occupants were ejected from the car on impact. Of three belted front seat occupants sustaining fatal injuries, two showed severe multiple injuries as a result of gross intrusion into the car and the third sustained severe injuries to the cervical spine in a car known to have been travelling at over 100 miles $(160 \mathrm{~km})$ an hour.

TABLE II-Mean injury severity scores of all car occupants injured and killed during February 1982 to January 1984

\begin{tabular}{|c|c|c|c|c|}
\hline \multirow[b]{2}{*}{$\begin{array}{l}\text { Category of car } \\
\text { occupant }\end{array}$} & \multicolumn{2}{|c|}{ February 1982 to January 1983} & \multicolumn{2}{|c|}{ February 1983 to January 1984} \\
\hline & $\begin{array}{c}\text { No } \\
\text { seat belt }\end{array}$ & $\begin{array}{l}\text { Wearing } \\
\text { seat belt }\end{array}$ & $\begin{array}{c}\text { No } \\
\text { seat belt }\end{array}$ & $\begin{array}{l}\text { Wearing } \\
\text { seat belt }\end{array}$ \\
\hline Drivers & $4 \cdot 74$ & 1.53 & $4 \cdot 71$ & 1.69 \\
\hline Front seat passengers & $4 \cdot 87$ & $1 \cdot 30$ & $4 \cdot 90$ & 1.45 \\
\hline Rear seat passengers & $4 \cdot 25$ & - & $3 \cdot 82$ & - \\
\hline
\end{tabular}

Serious (injury severity score greater than 12) but non-fatal injuries to drivers were noted. Before the introduction of seat belts $6.6 \%$ of injured drivers showed an injury severity score greater than 12 (mean 16.3) and a maximum score of $47 ; 40.7 \%$ had shown evidence of taking alcohol and $3.7 \%$ were wearing seat belts. After the introduction of legislation the mean injury severity score of severely injured drivers (that is, $3.4 \%$ of all drivers injured) was 20.0 with a maximum score of $35 ; 58.8 \%$ showed evidence of having taken alcohol and $47 \%$ had been wearing seat belts.

The number of front seat occupants admitted to hospital as a result of injuries sustained were studied for the two periods. From February 1982 to January 1983, 190 front seat occupants had injuries requiring admission to hospital; in the next 12 months 110 front seat occupants required admission. This represented a reduction of $42 \cdot 1 \%$ compared with the first period. In the 12 months from February 1983, of those front seat occupants who did require admission to hospital $34 \cdot 2 \%$ had not been wearing their seat belts at the time of the accident.

A reason for apparent non-compliance with seat belt legislation was sought and the following reasons emerged: forgetfulness, refusal, or possible inability to fasten the seat belt; overseas visitors who claimed not to realise that the law applied to them; inappropriate or ineffective seat belts-for example, lap strap type belts with no diagonal component; old cars in which seat belts were not fitted and were not required by law to be fitted.

The survey studied injuries sustained by back seat passengers. In the two year period a total of 432 back seat passengers were brought to the accident department having sustained injuries. In no case was there any record of this group of passengers having worn seat belts. ${ }^{14}$ The mean injury severity score of the back seat passengers was 4.03 , and in the two year period six back seat passengers sustained fatal injuries with a mean injury severity score of $67 \cdot 8$. In the period $1982-3$ back seat passengers constituted $16 \cdot 2 \%$ of the total car occupants recorded, and in the second 12 months they constituted $17 \cdot 3 \%$ of all car occupants.
Police information indicates that in East Berkshire, as elsewhere in Britain, roughly $95 \%$ of all front seat occupants of cars did comply with seat belt legislation.

\section{Discussion}

Few problems were encountered in using the scoring system. Two patients who sustained impaling injuries presented some difficulty in scoring, but in general the injury severity score correlated well with the clinical findings.

The findings of this survey were similar to those published elsewhere, in particular those from Australia. In analysing the reduction in severity of injury after seat belt legislation, severe injuries and deaths among front seat occupants were found to show an expected high level in the unbelted victims and gave further confirmation, if needed, of the importance of alcohol intoxication in driver victims.

Despite a $95 \%$ compliance rate with seat belt legislation after its introduction in the United Kingdom $14 \cdot 4 \%$ of front seat occupants sustaining injuries are known not to have been wearing seat belts.

A cause for concern must be the welfare of the back seat passengers, whose vulnerability to severe injury and death is unaffected by present seat belt legislation. Not only is the rear seat no longer the safe seat of the vehicle but the unbelted occupants in the rear seat are liable to sustain injuries twice as severe as those sustained by belted front seat occupants; hence it is reasonable to suggest that what appears to have been achieved so far by legislation in protecting the front seat occupants should be extended to providing increased protection for the rear seat occupants.

\section{References}

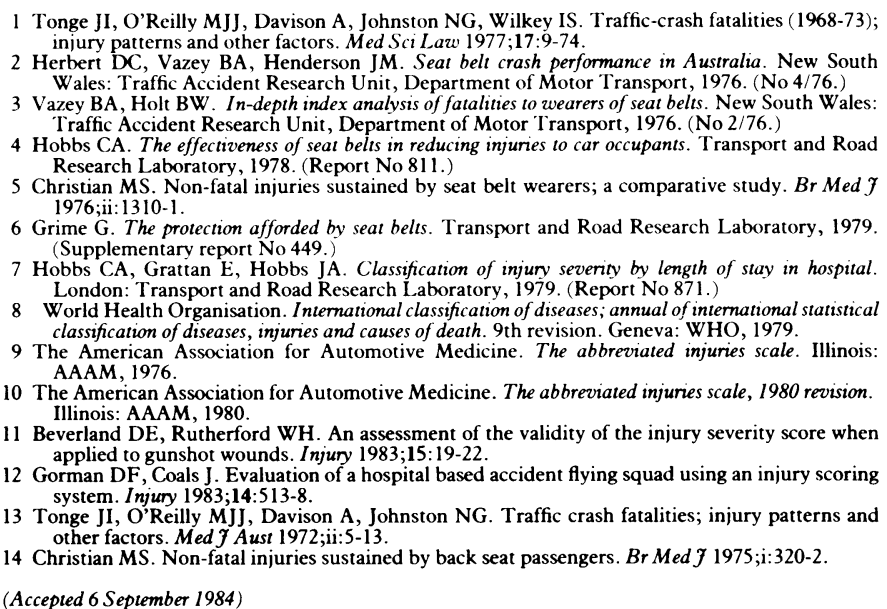

(Accepted 6 September 1984) 